\title{
The Application of the Taguchi Method in the Optimal Combination of the Parameters Design of the Spindle System
}

\author{
Di LIANG $^{1, a}$, Wei MENG ${ }^{2}$ \\ 1 School of Mechanical Engineering, Shenyang University, Shenyang, Liaoning Province, China \\ ${ }^{2}$ School of Mechanical Engineering, Shenyang University, Shenyang, Liaoning Province, China
}

\begin{abstract}
The paper combines with the application case in the field of parameter design of main spindle system. Firstly, the relevant parameters that affect the stability of the main spindle system transmission are determined, and then the Taguchi method and Minitab software are used to implement the orthogonal test for multiple factors. According to the experimental data, the analysis of signal to noise ratio and the analysis of variance are performed. Finally, the optimal combination of design parameters with different levels of spindle system is obtained. Case analysis shows that the Taguchi method has a significant effect on improving the transmission stability of the spindle system.
\end{abstract}

Keywords.the transmission stability of spindle system; Taguchi method; parameter design; Minitab; signal to noise ratio

\section{Introduction}

The Taguchi method was founded by Dr. Genichi Taguchi of Japan; its central content is regarded as Japan's "national treasure". The Taguchi method is widely used in automobile industry, mechanical manufacturing industry, electronic industry and other fields. In our country, colleges and the national defense science and technology industry have many theoretical researches on Taguchi method. Taguchi method is widely used in automobile manufacturing industry in the foreign countries, such as the U.S. automaker Ford and GM that apply the Taguchi method into practice, the cost of the two companies can be reduced, and the vehicle performance is improved, so Taguchi method gains remarkable achievements. In this paper, the thought of out-line quality control of Taguchi method is applied to the design stage of the spindle system.

\section{Taguchi method}

\subsection{Basic thought}

It is different from the traditional definition of quality; Dr. Genichi Taguchi defined the product quality as this [1]: The characteristic of avoiding causing losses to the society after the products get out of factories, the quality of products can be quantified by "quality loss". In order to improve the anti-interference ability of the product itself, Taguchi method can make the function and the property of products no insensitivity to the cause of deviation by adjusting the design parameters. In order to quantitatively describe the loss of product quality, Taguchi proposed the concept of "quality loss function [2]", and he used the signal-to-noise ratio to measure the stable level of designed parameters.

\subsection{Parameter design}

It means that the parameter design is carried out after the structure of the system is determined; the best combination of all parameters is found by using orthogonal experiment and the method of variance analysis. The so-called best combination is that the signal to noise ratio is introduced as evaluation indicator, the reliability, anti-interference, stability and uniform of products become stronger through the design of the stability.

\subsection{Signal to noise ratio}

In order to quantify the quality characteristics of the selected equipment, the concept of signal to noise ratio is introduced. Signal to noise ratios have three forms: The signal-to-noise ratio for the characteristic of nominal is best [3], the signal to noise ratio for the characteristic of smaller is best [4], the signal-to-noise ratio for the characteristic of larger is best.

\footnotetext{
${ }^{a}$ Corresponding author: sydxld@163.com
} 


\section{Instance verification}

The paper researches on the problem which occurred when a new type CNC machine tool is processing parts in the MX Company, the transmission of the main spindle system is not stable, and the parts' defective rate is also increased.

\subsection{Determine impact factors}

The experts of the product design department, production operation department and equipment management department determined the main factors affecting the stability of the main spindle system by using the brainstorming method.

\subsubsection{Controllable factors}

a--bearing support rigidity $(\mathrm{N} / \mathrm{m})$ : the increase of bearing support rigidity will enhance the stability of the spindle system.

b--spindle support type: The first support type is that the intermediate support bearings arrange in the place where the distance from the intermediate support bearings and the last support bearings is $35 \mathrm{~mm}$, the bearing span remains unchanged; the second support type is that one group of bearings selects individual bearing support, the last group of bearings selects three bearings support; the third support type is that there are three groups of bearings that arrange in the front, middle and back of the spindle, each group has two bearings.

c--bearing span $(\mathrm{mm})$ : The distance of adjacent two groups of bearings is called bearing span, this paper only considers the span of the first group of bearings and the last group of bearings.

$\mathrm{d}$--pre tightening force $(\mathrm{N})$ : Using appropriate methods to make certain pre deformation between the bearing rolling body and the ferrules is called pre tightening force.

e--spindle inside diameter $(\mathrm{mm})$ : The inside diameter of high speed spindle is a ladder shape, changing the inside diameter spindle will affect the rigidity of the spindle.

The transmission stability of the spindle system belongs to the dynamic characteristic of the spindle system. For the convenience of the study, this paper gives a simplified schematic diagram of the high speed spindle system.

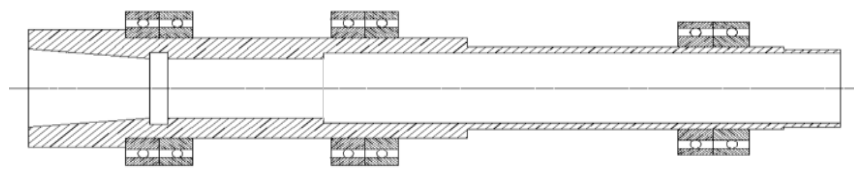

Figure 1. Simplified main spindle system.

\subsubsection{Noise factors}

M- Spindle materials; N-The cutter point pressure fluctuations when spindles are processed by machine tool (MPa); Q - Cutting fluid type

\subsection{Orthogonal test}

\subsubsection{Determine factors levels}

Table 1. Different levels of controllable factors

\begin{tabular}{|c|c|c|c|}
\hline factors & level1 & level2 & level3 \\
\hline $\mathrm{a}(\mathrm{N} / \mathrm{m})$ & $8 \times 10^{5}$ & $8 \times 10^{6}$ & $8 \times 10^{7}$ \\
\hline $\mathrm{b}$ & 1 & 2 & 3 \\
\hline $\mathrm{c}(\mathrm{mm})$ & 334 & 354 & 374 \\
\hline $\mathrm{d}(\mathrm{N})$ & 80 & 150 & 280 \\
\hline $\mathrm{e}(\mathrm{mm})$ & diameter -1 & diameter & diameter +1 \\
\hline
\end{tabular}

Table 2. Different levels of noise factors

\begin{tabular}{|c|c|c|}
\hline factors & level1 & level2 \\
\hline $\mathrm{M}$ & Import & Domestic \\
\hline $\mathrm{N}$ & 60 & 80 \\
\hline $\mathrm{Q}$ & $\mathrm{Q} 1$ & $\mathrm{Q} 2$ \\
\hline
\end{tabular}

\subsubsection{Make orthogonal table}

Table 3. Outer table of orthogonal test

\begin{tabular}{|c|c|c|c|c|}
\hline factors & \multicolumn{4}{|c|}{ levels } \\
\hline $\mathrm{M}$ & 1 & 1 & 2 & 2 \\
\hline $\mathrm{N}$ & 1 & 2 & 1 & 2 \\
\hline $\mathrm{Q}$ & 1 & 2 & 2 & 1 \\
\hline combine & $\mathrm{S} 1$ & $\mathrm{~S} 2$ & $\mathrm{~S} 3$ & $\mathrm{~S} 4$ \\
\hline
\end{tabular}

Firstly, the orthogonal table is created by the Minitab software, then according to the 27 combinations of different levels in the orthogonal table, the production department performs the on-site experiments, produces CNC machine tools, observes the operation condition of the spindle system of the CNC machine tools, tests the qualified condition of the parts that are processed by $\mathrm{CNC}$ machine tools, and records qualified rate of the parts. Finally, the orthogonal test is performed by using Minitab software and the result of the test is shown as follows.

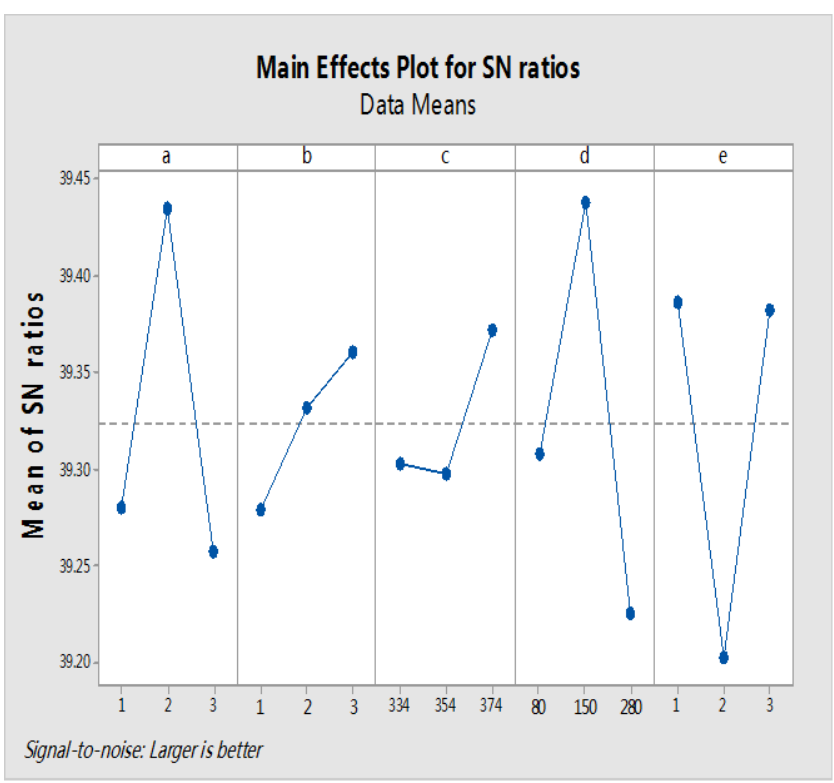

Figure 2. The main effect of each factor on signal to noise ratio. 


\begin{tabular}{|c|c|c|c|c|c|c|c|c|c|c|c|}
\hline+ & C1 & $\mathrm{C2}$ & $\mathrm{C3}$ & C4 & C5 & C6 & $\mathrm{CT}$ & C8 & $\mathrm{Cg}$ & C 10 & C 11 \\
\hline & $\mathbf{a}$ & $\mathbf{b}$ & c & d & $\mathbf{e}$ & S1 & s2 & S3 & S4 & SE & Mean \\
\hline 1 & 1 & 1 & 334 & 80 & 1 & 90.80 & 97.44 & 86.77 & 90.17 & 39.1863 & 91.2950 \\
\hline 2 & 1 & 1 & 334 & 80 & 2 & 87.44 & 85.80 & 89.00 & 90.97 & 38.9134 & 88.3025 \\
\hline 3 & 1 & 1 & 334 & 80 & 3 & 97.75 & 95.44 & 91.10 & 93.47 & 39.4943 & 94.4400 \\
\hline 4 & 1 & 2 & 354 & 150 & 1 & 96.43 & 95.44 & 94.13 & 93.47 & 39.5404 & 94.8675 \\
\hline 5 & 1 & 2 & 354 & 150 & 2 & 96.67 & 97.42 & 86.46 & 89.68 & 39.2951 & 92.5575 \\
\hline 6 & 1 & 2 & 354 & 150 & 3 & 90.61 & 92.32 & 93.14 & 92.55 & 39.2890 & 92.1550 \\
\hline $\mathbf{T}$ & 1 & 3 & 374 & 280 & 1 & 88.68 & 92.46 & 96.12 & 93.21 & 39.3231 & 92.6175 \\
\hline 8 & 1 & 3 & 374 & 280 & 2 & 90.72 & 90.77 & 94.11 & 90.17 & 39.2193 & 91.4425 \\
\hline 9 & 1 & 3 & 374 & 280 & 3 & 90.35 & 89.35 & 95.44 & 92.35 & 39.2555 & 91.8725 \\
\hline 10 & 2 & 1 & 354 & 280 & 1 & 97.75 & 91.79 & 91.13 & 91.79 & 39.3700 & 93.1150 \\
\hline 11 & 2 & 1 & 354 & 280 & 2 & 94.65 & 92.75 & 89.79 & 86.68 & 39.1632 & 90.9675 \\
\hline 12 & 2 & 1 & 354 & 280 & 3 & 95.48 & 89.77 & 91.75 & 90.75 & 39.2628 & 91.9375 \\
\hline 13 & 2 & 2 & 374 & 80 & 1 & 92.35 & 96.44 & 97.35 & 95.35 & 39.5833 & 95.3725 \\
\hline 14 & 2 & 2 & 374 & 80 & 2 & 90.75 & 91.72 & 93.31 & 92.15 & 39.2728 & 91.9825 \\
\hline 15 & 2 & 2 & 374 & 80 & 3 & 95.35 & 96.52 & 93.75 & 95.20 & 39.5718 & 95.2050 \\
\hline 16 & 2 & 3 & 334 & 150 & 1 & 96.76 & 98.59 & 95.35 & 97.35 & 39.7347 & 97.0125 \\
\hline 17 & 2 & 3 & 334 & 150 & 2 & 92.35 & 93.35 & 89.88 & 91.75 & 39.2574 & 91.8325 \\
\hline 18 & 2 & 3 & 334 & 150 & 3 & 97.38 & 98.21 & 96.89 & 94.20 & 39.7026 & 96.6700 \\
\hline 19 & 3 & 1 & 374 & 150 & 1 & 90.48 & 88.68 & 95.79 & 97.79 & 39.3661 & 93.1850 \\
\hline 20 & 3 & 1 & 374 & 150 & 2 & 93.72 & 87.77 & 95. 01 & 95.15 & 39.3471 & 92.9125 \\
\hline 21 & 3 & 1 & 374 & 150 & 3 & 97.79 & 89.38 & 98.02 & 89.68 & 39.4104 & 93.7175 \\
\hline 22 & 3 & 2 & 334 & 280 & 1 & 97.79 & 87.52 & 91.50 & 88.95 & 39.1996 & 91.4400 \\
\hline 23 & 3 & 2 & 334 & 280 & 2 & 90.75 & 90.35 & 91.13 & 92.06 & 39.1871 & 91.0725 \\
\hline 24 & 3 & 2 & 334 & 280 & 3 & 92.13 & 89.38 & 87.35 & 89.76 & 39.0468 & 89.6550 \\
\hline 25 & 3 & 3 & 354 & 80 & 1 & 92.47 & 88.68 & 90.36 & 92.65 & 39.1804 & 91.0400 \\
\hline 26 & 3 & 3 & 354 & 80 & 2 & 85.94 & 95.59 & 93.50 & 89.16 & 39.1630 & 91.0475 \\
\hline 27 & 3 & 3 & 354 & 80 & 3 & 95.44 & 87.75 & 95. 01 & 96.35 & 39.4105 & 93.6375 \\
\hline
\end{tabular}

Figure. 3 The orthogonal table created by Minitab

\subsection{The analysis of signal to noise ratios}

The figure. 2 shows that the second level of bearing support rigidity is better, the third level of bearing support type is better, the third level of bearing span is better, the second level of pre tightening force is better, the first level of spindle inside diameter is better.

\subsection{Variance analysis [5]}

Here is the formula for the sum of squares of factors

$S S=\frac{\mathrm{N}}{l} \sum_{i=1}^{n}\left(\bar{y}_{i}-\bar{y}\right)^{2}$

In the formula, $\mathrm{N}$ is the number of test; $l$ is the value of factor level; $\bar{y}_{i}$ is the mean of the characteristic value corresponding to the ' $\mathrm{i}$ ' level of the factor; $\overline{\mathrm{y}}$ is the mean of the characteristic value.

The formula for calculating the degree of freedom of factor:

$D O F=l-1$

The formula for calculating the variance of factor:

$V A R=S S / D O F$

This is the sum of squares of factor $a$.

$$
S S_{a}=\frac{\mathrm{N}}{l} \sum_{i=1}^{n}\left(\bar{y}_{i}-\bar{y}\right)=\frac{27}{3}\left[\begin{array}{l}
(92.17-92.64)^{2}+ \\
(93.79-92.64)^{2} \\
+(91.97-92.64)^{2}
\end{array}\right]
$$$$
=17.91
$$

The degree of freedom of factor $a$ :

$$
D O F_{a}=l_{a}-1=2
$$

The variance of factor $a$ :

$$
V A R_{a}=S S_{a} / D O F_{a}=8.954
$$

The sum of squares of residuals of the factor $a$ :

$S S_{\text {error }}=34.117$ (Derived from Minitab)

The degree of freedom of residual of the factor $a$ :

$$
D O F_{\text {error }}=n-1-\sum D O F=27-1-2 \times 5=16
$$

The residual variance of factor $a$

$$
V A R_{\text {error }}=S S_{\text {error }} / D O F_{\text {error }}=2.132
$$

The variance ratio of factor $a$ :

$$
\mathrm{F}=V A R_{a} / V A R_{\text {error }}=4.2
$$

In the same way, other factors can be calculated and the variance analysis of the mean of the quality characteristic and the variance analysis of the signal to noise ratio are shown as follows

Table 4. Variance analysis of mean

\begin{tabular}{|c|c|c|c|c|c|c|}
\hline source & df & Seq SS & Adj SS & AdjMS & F & P \\
\hline a & 2 & 17.91 & 17.91 & 8.95 & 4.20 & 0.034 \\
\hline b & 2 & 3.006 & 3.006 & 1.503 & 0.70 & 0.509 \\
\hline c & 2 & 3.419 & 3.419 & 1.709 & 0.80 & 0.466 \\
\hline d & 2 & 24.37 & 24.37 & 12.18 & 5.71 & 0.013 \\
\hline e & 2 & 22.71 & 22.71 & 11.36 & 5.32 & 0.017 \\
\hline error & 16 & 34.12 & 34.12 & 2.132 & & \\
\hline
\end{tabular}

Table 5. Variance analysis of signal to noise ratio

\begin{tabular}{|c|c|c|c|c|c|c|}
\hline source & df & Seq SS & Adj SS & AdjMS & F & P \\
\hline a & 2 & 0.170 & 0.170 & 0.085 & 4.61 & 0.026 \\
\hline b & 2 & 0.031 & 0.031 & 0.015 & 0.83 & 0.454 \\
\hline c & 2 & 0.032 & 0.032 & 0.016 & 0.85 & 0.445 \\
\hline d & 2 & 0.207 & 0.207 & 0.104 & 5.61 & 0.014 \\
\hline e & 2 & 0.201 & 0.201 & 0.100 & 5.43 & 0.016 \\
\hline
\end{tabular}




\begin{tabular}{|l|l|l|l|l|l|l|}
\hline error & 16 & 0.295 & 0.295 & 0.018 & & \\
\hline
\end{tabular}

From the Table 4, we can see that the value of $\mathrm{P}$ is less than 0.05 for the factor $a, d$ and $e$, so these factors are significant to the mean of the quality characteristic value. From the Table 5, we can see that the value of $\mathrm{P}$ is also less than 0.05 for the factor $a, d$ and $e$, so these three factors are significant to the signal to noise ratio.

According to the variance analysis, we can know that the factors $a, d, e$ have a significant effect on the signalto-noise ratio and the mean of quality characteristic, so the three factors are important factors, the figure. 2 shows that the level of factors $a, d$, and $e$ should respectively select $a 2, d 2$, and $e 1$. The effects of $b$ and $c$ on signal-tonoise ratio and the mean of the quality characteristic value are not very obvious, so they are minor factors, it indicated that the bearing support type and bearing span are not the main parameters that influence the dynamic characteristics of the spindle system, but it would impact on the flexibility of spindle if the span of the front and the back bearings is too big, so it is better for $c$ to select the second level, and according to the signal-to-noise ratio response figure, factor $b$ should select $b 3$, finally the best combination of factor level is $a 2, b 3, \mathrm{c} 2, d 2, e 1$.

\section{Conclusion}

This paper has a in-depth study on the problem of unqualified parts that are made by the CNC machine tools of MX company, the research shows that the parameter design of the spindle system is not reasonable, this makes the spindle system transmission is not stable, and the anti vibration property is weak so that the accuracy of processing parts is not high and the qualified rate is low. In this paper, the main parameters affecting the dynamic characteristics of the spindle system and their levels are determined by using the brainstorming method, and the orthogonal experiment, the signal to noise ratio analysis, and variance analysis are carried on by using the Taguchi method and Minitab software, finally the optimal combination of design parameters of the spindle system is determined, then the production department does the production test with the optimal combination of parameters. The test result shows that the qualified rate of parts processed by machine tools is increased from $88.66 \%$ to $95.85 \%$ compared with before; production efficiency is also increased by $10 \%$.

\section{References}

1. Z.J. Han, W.J. Zhang, Quality engineering-the quality management of out-line and on-line, Science Press, Beijing, 1991, pp. 33-37.

2. AI Wu, The second edition of quality management, edition, Jinan University press, Zhanjiang, 2004, pp. 20-25.

3. Genichi Taguchi, Development and design phase of the quality engineering, Japan specifications Association, 2011, pp. 11.

4. G.X. Wang, Z.J. Han, The relationship of quality loss and signal to noise ratio between the 'Larger is best' and 'Smaller is best', Mechanical science and technology, J. 19 (2000)236-238.

5. X.R. Shi, C.B. Yang, and Q.H. Hong, Optimal design of HPLC Chinese medicinal composition testing based on Taguchi and ANOVA methods, Strait pharmaceutical, J. 20(2008) 45-47. 